\title{
Depressive symptoms in rheumatoid arthritis patients
}

\section{Sintomas depressivos em pacientes com artrite reumatoide}

\author{
Lucas Francisco Botequio Mella, ${ }^{1}$ Manoel Barros Bértolo, ${ }^{2}$ Paulo Dalgalarrondo ${ }^{1}$ \\ ${ }^{1}$ Department of Medical Psychology and Psychiatry, Faculdade de Ciências Médicas (FCM), Universidade Estadual de Campinas (UNICAMP), \\ Campinas, SP, Brazil \\ ${ }^{2}$ Department of Internal Medicine, Faculdade de Ciêncas Médicas (FCM), Universidade Estadual de Campinas (UNICAMP), Campinas, SP, Brazil
}

\begin{abstract}
Objective: To determine the prevalence of depressive and anxiety symptoms in patients with rheumatoid arthritis (a chronic inflammatory disease) in comparison to a control group with osteoarthritis (a chronic non-inflammatory degenerative disease) and to identify the sociodemographic and clinical variables associated with depressive symptoms in these patients. Method: Sixty-two rheumatoid arthritis patients and 60 osteoarthritis patients participated in the study. Sociodemographic and clinical data were collected and the Hospital Anxiety and Depression Scale and the Disability Index of the Health Assessment Questionnaire were applied. Results: The prevalence of depressive symptoms was of $53.2 \%$ in rheumatoid arthritis and $28.3 \%$ in osteoarthritis $(\mathrm{p}=0.005)$. The prevalence of anxiety symptoms was of $48.4 \%$ in rheumatoid arthritis and $50.0 \%$ in osteoarthritis ( $\mathrm{p}=0.859)$. The mean (and standard deviation) scores in the Disability Index of the Health Assessment Questionnaire were 1.4 (0.8) in rheumatoid arthritis and $1.4(0.6)$ in osteoarthritis $(\mathrm{p}=0.864)$. Rheumatoid arthritis patients with depressive symptoms had lower education and higher disease activity and functional disability. Conclusion: Although these two rheumatic diseases are similar in terms of the pain and functional disability that they cause, a significantly higher prevalence of depressive symptoms was found in rheumatoid arthritis patients. This difference might be explained by the hypothesis of a neuroimmunobiological mechanism related to cytokines in inflammatory diseases, which has been considered as a candidate to the development of depressive symptoms.
\end{abstract}

Descriptors: Depression; Arthritis, rheumatoid; Psychoneuroimmunology; Anxiety; Osteoarthritis
Resumo

Objetivo: Determinar a prevalência de sintomas depressivos e ansiosos na artrite reumatoide (doença inflamatória crônica) em comparação com um grupo controle com osteoartrite (doença crônico-degenerativa não inflamatória). Identificar variáveis sociodemográficas e clinicas associadas a sintomas depressivos nesses pacientes. Método: Participaram do estudo 62 pacientes com artrite reumatoide e 60 pacientes com osteoartrite. Foram coletados dados sociodemográficos e clínicos e foram aplicadas as escalas Hospital Anxiety and Depression Scale e Disability Index of the Health Assessment Questionnaire. Resultados: A prevalência dos sintomas depressivos foi $53,2 \%$ na artrite reumatoide e 28,3\% na osteoartrite ( $p=0,005)$. A prevalência dos sintomas ansiosos foi $48,4 \%$ na artrite reumatoide e 50,0\% na osteoartrite ( $p=0,859)$. Os valores médios (desvio padrão) de Disability Index of the Health Assessment Questionnaire foram $1,4(0,8)$ na artrite reumatoide e $1,4(0,6)$ na osteoartrite $(p=0,864)$. Pacientes com artrite reumatoide e sintomas depressivos apresentaram menor nivel educacional e maiores niveis de atividade da doença e incapacidade funcional. Conclusão: Embora ambas as doenças reumatológicas sejam similares em termos de dor e incapacidade funcional, uma prevalência significativamente maior de sintomas depressivos na artrite reumatoide foi encontrada. Essa diferença poderia ser explicada por meio da hipótese de um mecanismo neuroimunobiológico relacionado às citocinas nas doenças inflamatórias, o qual vem sendo considerado candidato para o desenvolvimento de sintomas depressivos.

Descritores: Depressão; Artrite reumatoide; Psiconeuroimunologia; Ansiedade; Osteoartrite

\section{Introduction}

Rheumatoid arthritis (RA) is a systemic, chronic, and inflammatory disease with probable autoimmune etiology and predominant involvement of joints, characterized by symmetrical peripheral polyarthritis, resulting in joint deformity. ${ }^{1}$ In addition to producing a chronic inflammatory state, the disease generally causes many harmful psychosocial consequences for patients. Continuous pain, functional disability, tiredness, incapacity to work, economic limitations, and side effects of therapeutic drugs, which RA may bring about, can end up reducing these patients' quality of life. ${ }^{2,3}$ Commonly associated with these biopsychosocial 
problems, psychiatric symptoms - especially depressive and anxiety ones - are relatively frequent in RA patients.

Several studies have identified depressive symptoms as an important aspect in RA. The prevalence of depressive symptoms in RA has been reported to vary between $6 \%$ and $65 \%$, according to the screening methods used and to the samples studied. ${ }^{4-9} \mathrm{~A}$ recent review described a mean prevalence of $19 \%$ of depression among RA patients. ${ }^{3}$ Anxiety symptoms and disorders have been less studied separately, because they are a very frequent dimension of depression, making it difficult to separate anxiety symptoms from depressive ones. ${ }^{10}$ Some studies have found a prevalence of almost $40 \%$ of anxiety symptoms in RA. ${ }^{11}$

Two main hypotheses have been proposed to explain the association between RA and depressive manifestations: 1) the functional disability and poor quality of life could provoke the emergence of depressive symptoms or 2) a common neuroimmunobiological mechanism could underlie the development of RA and depression. This last hypothesis has been supported by a model according to which depressive symptoms and major depression are related to psychoneuroimmunological disturbances. The immune system activation and the resulting proinflammatory cytokine release have been associated with neurochemical, neuroendocrine, and behavioral abnormalities related to depressive disorders. Cytokines are causally related to the activation of the enzyme indoleamine-2,3-dioxygenase (IDO), with the consequent reduction of tryptophan (serotonin precursor) levels and serotonin synthesis, which is a neurochemical process reported to be implied in major depression. Cytokine release has also been linked to hypothalamic-pituitary-adrenal (HPA) axis hyperactivity, a neuroendocrine abnormality associated with depression. Finally, cytokine serum levels seem to be positively correlated with symptoms such as appetite loss, anorexia, weight loss, fatigue, sleep disturbances, motor retardation, reduced libido, cognitive impairment, anhedonia, and depressed mood, which are frequent in depressive disorders. ${ }^{12}$ Therefore, according to this model, the presence of depressive symptoms in RA may be more than a psychological reaction to the pain and functional disability related to the disease and may represent a dimension of the chronic inflammation status of RA; in this case, depressive symptoms would be in fact related to cytokine release itself. ${ }^{12-16}$

In order to epidemiologically survey these hypotheses, AbdelNasser et al. and Bagnato et al. compared the prevalence of depressive symptoms in RA and osteoarthritis (OA), another chronic rheumatic disease that causes pain and functional disability. ${ }^{711}$ Differently from RA, OA is essentially degenerative and non-inflammatory. Both studies reported higher levels of depressive and anxiety symptoms among RA patients compared to OA ones.

Other investigations have addressed the sociodemographic and clinical characteristics of RA in relation to the presence of depressive symptoms. These symptoms have been commonly associated with low levels of physical activity, low education and income, unemployment, functional disability, morning stiffness, joint pain, fatigue, duration of illness, permanent joint deformities, active inflammation, and high dependence on health services. ${ }^{5,17-19}$
However, most studies have not been conclusive in regard to the profile of patients with RA and depressive symptoms ${ }^{7,8}$ due to differences in the studied samples and the heterogeneous criteria used to define and screen for depressive manifestations. ${ }^{9}$

The objectives of the present study were 1) to establish the prevalence of depressive and anxiety symptoms in RA patients treated at an outpatient rheumatology service in an university hospital; 2) to compare the prevalence of depressive and anxiety symptoms in RA and in a control group with OA; and 3) to compare two subgroups of RA patients - with and without depressive symptoms - concerning sociodemographic and clinical variables.

\section{Method}

This study comprised 122 patients from the rheumatoid arthritis out-patient service and the degenerative diseases outpatient service of the hospital of the Universidade Estadual de Campinas (UNICAMP). Sixty-two patients were diagnosed with RA, according to the American College of Rheumatology (ACR) criteria, ${ }^{20}$ and 60 were diagnosed with osteoarthritis (OA), based on clinical and radiological criteria. ${ }^{21}$ The exclusion criteria were: undefined RA or OA diagnosis, presence of a concomitant disease that can be responsible for clinical and laboratorial manifestations similar to those of RA or OA or likely to induce depressive and anxiety symptoms (cancer, use of medicines, infections, other immunological and rheumatologic diseases, psychiatric disorders).

The data were collected after medical appointments. When the inclusion and exclusion criteria were fulfilled, patients were invited to voluntarily participate in the study and to read and sign an informed consent statement. The data were collected by interview, questionnaire, joint exam, and copy of laboratory results from medical files. The selection of patients was consecutive and the evaluator was not blinded in regard to the rheumatologic diagnosis, because the patients in each group were recruited from different outpatient services of the same hospital.

The sociodemographic variables assessed were gender, age, marital status, education, occupation, residence, religion, religious practice, and religiosity (faith).

Depression and anxiety symptoms were evaluated using the Hospital Anxiety and Depression (HAD) scale. It contains seven items screening for anxiety and seven for depression, rated from zero to three. Scores over seven in each subscale are suggestive of anxiety or depressive disorders. ${ }^{22}$ This scale was especially developed in order to avoid an overestimation of affective symptoms, which are frequent in physically ill patients. The HAD scale has been translated into Portuguese and validated for Brazilian samples. ${ }^{23,24}$

RA and OA patients were also assessed in regard to functional disability using the Disability Index of the Stanford Health Assessment Questionnaire (HAQ-DI), translated and validated for Brazilian samples. ${ }^{25}$ This scale consists of 20 questions related to the level of difficulty to perform daily activities, considering pain and joint limitations. The questions are divided into eight areas of daily activities and the final score is defined by adding up 
the higher scores in each area and dividing the result by eight, so that the final index varies from zero to three. ${ }^{26}$

Clinical variables from RA patients included age at onset, duration of illness, extra-joint manifestation, morning stiffness, rheumatoid factor (RF), and disease activity. The "Disease Activity Score" for 28 joints (DAS 28) was used to evaluate RA activity and to classify it as low (score $<3.2$ ), moderate (scores between 3.2 and 5.1) or high (score > 5.1). This score was calculated after four variables: number of painful joints, number of swollen joints, erythrocyte sedimentation rate (ESR), and visual analogue scale (VAS - values between 0 and 100), aiming to evaluate patients in a global way. ${ }^{27}$ The treatment for RA was checked in relation to disease-modifying anti-rheumatic drugs (DMARD) (sulfasalazine, methotrexate, leflunomide), glucocorticoids and/or anti-tumor necrosis factor (TNF)-alpha biological agents (etanercept, infliximab, adalimumab). ${ }^{28}$

\section{Ethical considerations}

The study was approved by the Faculdade de Ciências Médicas (FCM) Research Ethics Committee of the Universidade Estadual de Campinas (UNICAMP), under the number 165/2006.

\section{Statistical analysis}

This was an observational and cross-sectional study to investigate associations and compare proportions. The Chi-Square and Fisher's exact test were used as necessary, and the multiple logistic regression analysis was adjusted according to age. The Shapiro-Wilk pocedure was used to test the null hypothesis that samples represented a normally distributed population. In order to compare continuous and ordinal measures between the two groups, the Mann-Whitney and Analysis of Variance methods were used for age adjustment. The level of significance was set at $\mathrm{p}<0.05$.

\section{Results}

Table 1 shows the sociodemographic profiles of the RA and OA groups. When the groups were compared, no statistically significant differences were found with regard to gender, marital status, education, occupation, residence (urban or rural), religion, religious practice, and religiosity (faith). However, there was a difference in regard to the age of the patients.

Among RA patients, 33 (53.2\%) had depression symptoms and $30(48.4 \%)$ had anxiety symptoms according to the HAD scale. Among the patients in the OA control group, 17 (28.3\%) presented with depression and $30(50.0 \%)$ with anxiety. When the two groups were compared, a statistically significant higher prevalence of depressive symptoms was found in RA patients, which did not occur concerning anxiety symptoms (Figure 1 ). The comparison of the prevalence of depressive and anxiety symptoms in RA and OA was redone with age adjustment $(\mathrm{p}=0.065$, $\beta_{0}=1.063, \beta_{1}=-0.033$ for depressive and $p=0.362, \beta_{0}=1.805$, $\beta_{1}=-0.015$ for anxiety symptoms). Additionally, 40 to 60 year-

Table 1 - Sociodemographic characteristics of RA and OA patients

\begin{tabular}{|c|c|c|c|}
\hline & RA ( $n=62)$ & $O A(n=60)$ & $\mathbf{p}$ \\
\hline Females & $83.9 \%$ & $80.0 \%$ & 0.578 \\
\hline Age in years - mean (SD) & $51.1(12.8)$ & $61.3(11.6)$ & $<0.001$ \\
\hline Marital status & & & 1.000 \\
\hline Single & $4.8 \%$ & $3.3 \%$ & \\
\hline Married & $69.4 \%$ & $71.7 \%$ & \\
\hline Widow/widower & $19.4 \%$ & $20.0 \%$ & \\
\hline Divorced & $6.5 \%$ & $5.0 \%$ & \\
\hline Education & & & 0.143 \\
\hline Illiterate or preschool or incomplete elementary school & $66.1 \%$ & $83.3 \%$ & \\
\hline Complete elementary school or incomplete high school & $11.3 \%$ & $8.3 \%$ & \\
\hline Complete high school or incomplete college & $17.7 \%$ & $6.7 \%$ & \\
\hline Complete college or postgraduate studies & $4.8 \%$ & $1.7 \%$ & \\
\hline Occupation & & & 0.763 \\
\hline Unemployed & $21.0 \%$ & $23.3 \%$ & \\
\hline Housewife & $53.2 \%$ & $53.3 \%$ & \\
\hline Temporary job & $8.1 \%$ & $3.3 \%$ & \\
\hline Permanent job & $17.7 \%$ & $20.0 \%$ & \\
\hline Residence (urban) & $85.5 \%$ & $95.0 \%$ & 0.078 \\
\hline Religion (catholic) & $66.1 \%$ & $58.3 \%$ & 0.374 \\
\hline Religious practice (practitioner) & $80.7 \%$ & $88.3 \%$ & 0.242 \\
\hline Religiosity/faith & & & 0.505 \\
\hline Less & $6.5 \%$ & $1.7 \%$ & \\
\hline Moderate & $16.1 \%$ & $16.7 \%$ & \\
\hline Much & $77.4 \%$ & $81.7 \%$ & \\
\hline
\end{tabular}

RA: rheumatoid arthritis; $O A$ : osteoarthritis; $S D$ : standard deviation 
RA (n=62) $\square \mathrm{OA}(\mathrm{n}=60)$

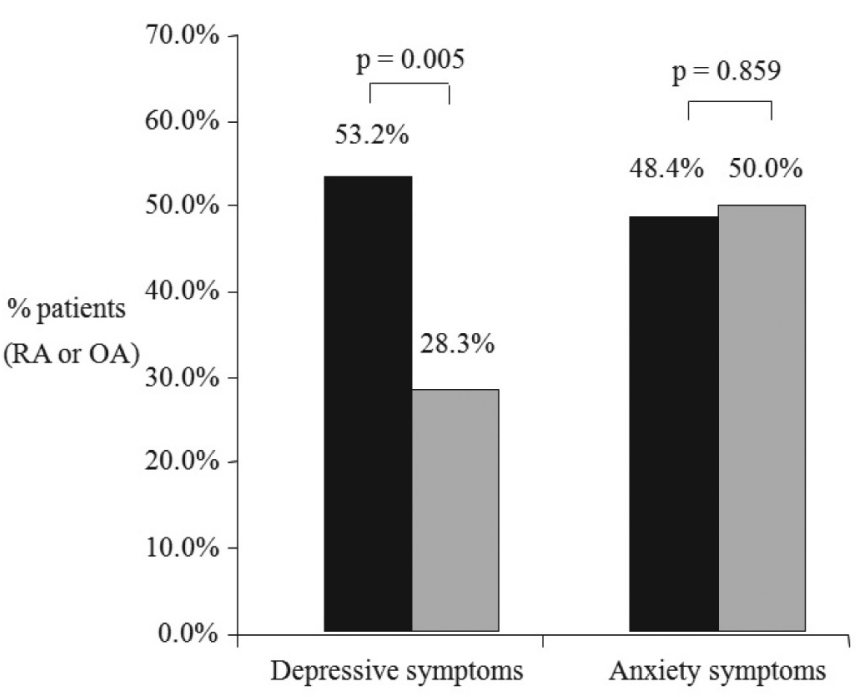

Figure 1 - Prevalence of depressive and anxiety symptoms in RA and OA patients.

$R A$ : rheumatoid arthritis; $O A$ : osteoarthritis

old patients were selected to homogenize the samples. As a result, the analysis indicated a rate of $53.3 \%$ of anxiety symptoms in RA versus $52.2 \%$ in OA ( $\mathrm{p}=0.933$ ), and of $56.7 \%$ of depressive symptoms in RA versus $30.4 \%$ in OA patients ( $p=0.057$ ). In these new analyses, despite the reduction in the statistical significance, a tendency for higher depression scores in RA than in OA continued to be observed.

There was no statistically significant difference between groups in relation to the level of functional disability. RA patients presented a mean (and standard deviation) HAQ-DI score of 1.4 (0.8) - median of 1.4, maximum equal to 3.0 and minimum 0 and OA patients presented a mean score of $1.4(0.6)$ - median of 1.4, maximum equal to 2.9 and minimum 0 (Figure 2).

In the next phase, RA patients were divided into two groups - with and without depression - according to the scores in the HAD scale, and compared in terms of sociodemographic, clinical, functional disability, and treatment variables. The overall clinical profile of RA patients consisted of a mean (SD) age at onset of 35.5 (13.9) years, mean duration of illness of 15.6 (13.0) years, extra-joint manifestation of $29.0 \%$, morning stiffness of $85.5 \%$, positive rheumatoid factor of $69.4 \%$, DAS 28 of 4.8 (1.7), and HAQ-DI of 1.37 (0.83).

There were no statistical differences between the groups with and without depressive symptoms concerning gender, age, residence (urban or rural), religion, religious practice, and clinical variables. However, RA patients with depressive symptoms presented a lower educational level, a higher disease activity rate (taking into account not only the prevalence of high disease activity, but also DAS 28 scores), and a higher functional disability index than patients without depressive symptoms (Table 2 ). Furthermore, the groups were not different in relation to marital status ( $\mathrm{p}=0.891$ ), occupation [unemployed, housewife, temporary

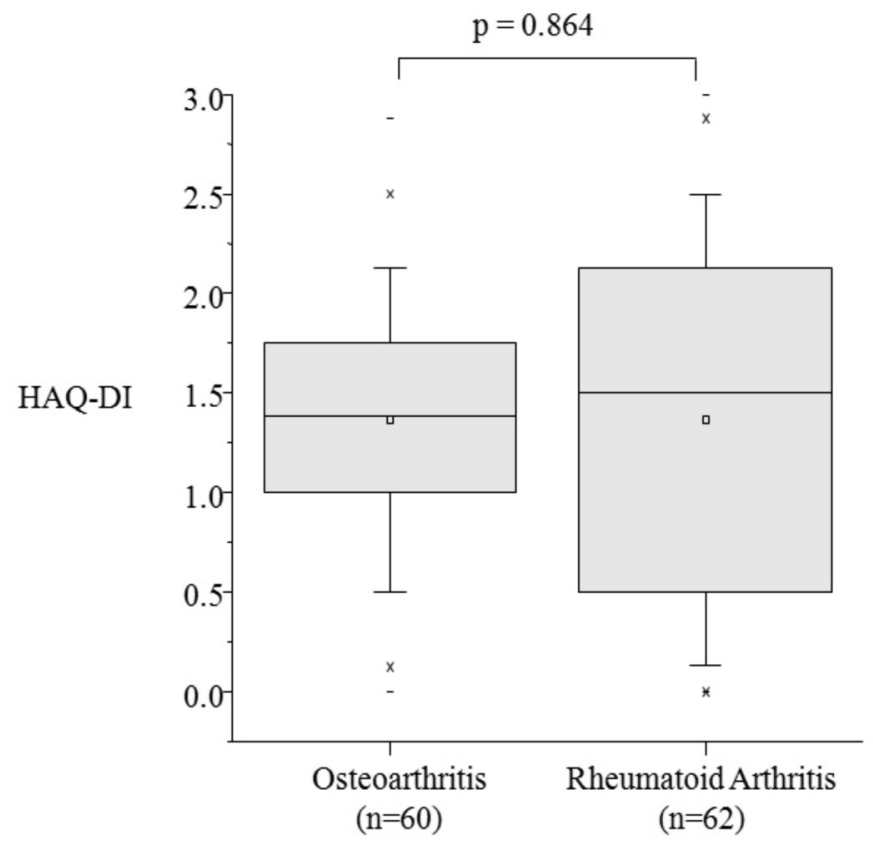

Figure 2 - Comparison of functional disability levels in osteoarthritis and rheumatoid arthritis measured by the Disability Index of the Stanford Health Assessment Questionnaire (HAQ-DI).

job, and permanent job $(\mathrm{p}=0.818)$ ], and religiosity/faith [less, moderate, and much $(\mathrm{p}=0.167)]$. Concerning the treatment for RA, DMARD, glucocorticoids, and biological agents were checked as non-mutually excluding variables and there was no difference between groups with and without depressive symptoms related to drugs for RA ( $\mathrm{p}=1,0.819$ and 0.878 , respectively).

\section{Discussion}

The present study indicated a high prevalence of depressive symptoms in RA, consonant with previous investigations. ${ }^{4-9}$ The prevalence of anxiety symptoms found in RA was higher than that expected in relation to previous evidence. ${ }^{11}$ Nevertheless, the present data may be overestimating the frequency of depressive and anxiety symptoms in RA by considering community samples. It should be kept in mind that the samples here investigated come from a university hospital, which tends to care for the most severe cases. On the other hand, such bias may not be relevant when the two conditions (RA and OA) are compared, due to the fact that patients came from the same care center and the two diseases have similar clinical severity.

In addition, it is possible that the method for measuring depressive and anxiety symptoms used in many studies ${ }^{4-9,11}$ might be accountable for the high prevalence of these features commonly found in RA. However, in the present study we tried to control for this methodological effect. Differently from other investigations, the depression and anxiety questionnaire used here (HAD) was specifically designed to screen for psychiatric symptoms in patients with physical diseases. Therefore, it eliminates false-positive responses related to somatic symptoms. Thus, the HAD seems to prevent the overestimation of depression and anxiety levels 
Table 2 - Rheumatoid arthritis patients with and without depressive symptoms

\begin{tabular}{|c|c|c|c|}
\hline & $\begin{array}{c}\text { No depressive } \\
\text { symptoms }(n=29)\end{array}$ & $\begin{array}{l}\text { Depressive symptoms } \\
\qquad(\mathrm{n}=33)\end{array}$ & p \\
\hline Females & $75.9 \%$ & $90.9 \%$ & 0.167 \\
\hline Age in years - mean (SD) & $53.1(13.9)$ & $49.4(11.6)$ & 0.169 \\
\hline Education & & & 0.040 \\
\hline Illiterate or preschool or incomplete elementary school & $55.2 \%$ & $75.8 \%$ & \\
\hline Complete elementary school or incomplete high school & $6.9 \%$ & $15.2 \%$ & \\
\hline Complete high school or incomplete college & $31.0 \%$ & $6.1 \%$ & \\
\hline Complete college or postgraduate study & $6.9 \%$ & $3.0 \%$ & \\
\hline Residence (urban) & $82.8 \%$ & $87.9 \%$ & 0.722 \\
\hline Religion (catholic) & $65.5 \%$ & $66.7 \%$ & 0.924 \\
\hline Religious practice (practitioner) & $89.7 \%$ & $72.7 \%$ & 0.092 \\
\hline Onset age in years, mean (SD) & $37.3(15.7)$ & $33.5(12.1)$ & 0.194 \\
\hline Duration in years, mean (SD) & $15.5(12.2)$ & $15.7(13.8)$ & 0.724 \\
\hline Extra-joint manifestation & $27.6 \%$ & $30.3 \%$ & 0.814 \\
\hline Morning stiffness & $79.3 \%$ & $90.9 \%$ & 0.283 \\
\hline Positive rheumatoid factor & $62.1 \%$ & $75.8 \%$ & 0.243 \\
\hline Disease activity & & & 0.007 \\
\hline Low & $31.0 \%$ & $6.1 \%$ & \\
\hline Moderate & $44.8 \%$ & $36.4 \%$ & \\
\hline High & $24.1 \%$ & $57.6 \%$ & \\
\hline DAS 28 - mean (SD) & $4.1(1.6)$ & $5.5(1.6)$ & 0.003 \\
\hline HAQ-DI - mean (SD) & $0.98(0.74)$ & $1.7(0.77)$ & 0.001 \\
\hline
\end{tabular}

SD: standard deviation; DAS 28: disease activity score for 28 joints; HAQ-DI: disability index of the Stanford Health Assessment Questionnaire

in patients with organic conditions and comorbid anxiety and depressive symptoms, such as RA and OA patients.

Comparing the RA and OA groups, the prevalence of depressive symptoms in the former was higher than in the latter $(p=0.005)$. This did not occur in relation to anxiety symptoms, which were similar in both groups. There were no differences concerning most of the sociodemographic characteristics that could influence the prevalence of depressive and anxiety symptoms, except the mean age.

There was a reduction in the significance of the higher prevalence of depression in RA versus OA after the adjustment for age. However, in all the analyses conducted, depressive symptoms were more prevalent in RA than in OA, and this difference had either statistical significance or tendency. It is probable that a type II error has occurred here, i.e. the number of patients in the groups selected was not sufficient to detect a statistically significant difference, although it might exist ${ }^{29}$ as suggested by the comparison without adjustment for age.

Another purpose of this study was to analyze which variables were related to depressive symptoms in RA patients. The results revealed that depressive symptoms are associated with low educational level, high disease activity, and high functional disability. Low educational levels are commonly associated with lower professional expectations, purchasing power, access to leisure, and understanding about one's own disease (RA) - facts that may explain the higher rates of depressive complaints in some individuals. Moreover, higher HAQ-DI scores in patients with depressive symptoms may suggest that RA-related functional disability is also responsible for the high frequency of depressive manifestations in this disease.

High functional disability levels resultant from RA and/or a possible neuroimmunobiological mechanism could explain the high frequency of depressive symptoms found in RA. In order to investigate the hypothesis that considers depression as secondary to the physiopathology of RA, the prevalence of depressive symptoms in RA was compared with the prevalence of depressive symptoms in a disease with a similar impact, but presenting a different physiopathology from RA. OA also causes pain and joint deformities in patients; however, it is predominantly chronicdegenerative and not inflammatory like RA. In this comparison, both patient groups presented the same levels of impairment and suffering, that is, similar levels of functional disability stemming from pain and joint deformities, demonstrated by similar average HAQ-DI scores in the OA and RA groups. On the other hand, the prevalence of depressive symptoms was higher in RA than in OA. Therefore, this difference could be due to the inflammatory nature of RA, characterized by increased proinflammatory cytokine release, which would cause neurochemical, neuroendocrine, and behavioral changes associated with depression. ${ }^{12}$

It was already expected that depressive symptoms in RA would be related to high disease activity, measured with the DAS 28. The more active RA is, the greater the inflammation, cytokine release, and functional disability associated with it, a cluster of biological phenomena that may be one of the most relevant aspects of depression in RA. 
This study has some methodological limitations which must be considered in the analysis of the results. There are some variables that were not evaluated here and that could influence the comparison of the prevalence of depressive symptoms in RA versus $\mathrm{OA}$, such as age at onset and duration of illness. Moreover, the use of some drugs can induce depressive and anxiety symptoms (e.g. corticosteroids and immunosuppressants). The HAD scale identifies only current depressive and anxiety symptoms, and although it can suggest a diagnosis of depressive or anxiety disorders, it is unable to establish such a diagnosis. The absence of confirmed diagnoses and the lack of data about age at onset of major depression, which could be compared with age at onset of RA, are factors that limit a possible cause-effect analysis. Furthermore, it was not the scope of this study to confirm or to refute the hypothesis that depressive symptoms are secondary to a neuroimmunobiological mechanism. Similarly, it was not methodologically possible to suggest any direct relationship between these results and a neuroimmunobiological theory associating RA and depressive symptoms.

The present findings suggest that the emergence of depressive symptoms in RA patients is not only related to subjective suffering and physical limitations caused by the disease. In this context, it is plausible that a neuroimmunobiological mechanism, among other possible factors, could be associated with the development of depressive symptoms. This study may, therefore, contribute to an integrated and psychosomatic view for the comprehension of RA, taking into account the high frequency of depressive symptoms present in this condition.

\section{Acknowledgements}

The authors are grateful to the participants. This research was supported by grants from the Fundação de Amparo à Pesquisa do Estado de São Paulo (FAPESP) and the Conselho Nacional de Desenvolvimento Científico e Tecnológico (CNPq) of Brazil. The authors report no potential conflicts of interest.

\section{Disclosures}

\begin{tabular}{|c|c|c|c|c|c|c|c|}
\hline $\begin{array}{l}\text { Writing group } \\
\text { member }\end{array}$ & Employment & $\begin{array}{l}\text { Research } \\
\text { grant }^{1}\end{array}$ & $\begin{array}{l}\text { Other research grant or } \\
\text { medical continuous } \\
\text { education }\end{array}$ & $\begin{array}{l}\text { Speaker's } \\
\text { honoraria }\end{array}$ & $\begin{array}{c}\text { Ownership } \\
\text { interest }\end{array}$ & $\begin{array}{l}\text { Consultant/ } \\
\text { Advisory } \\
\text { board }\end{array}$ & Other ${ }^{3}$ \\
\hline $\begin{array}{l}\text { Lucas Francisco } \\
\text { Botequio Mella }\end{array}$ & $\begin{array}{c}\text { FCM- } \\
\text { UNICAMP }\end{array}$ & $\begin{array}{l}\text { FAPESP* } \\
\text { CNPq }^{*}\end{array}$ & - & - & - & - & - \\
\hline $\begin{array}{l}\text { Manoel Barros } \\
\text { Bértolo }\end{array}$ & $\begin{array}{c}\text { FCM- } \\
\text { UNICAMP }\end{array}$ & FAPESP*** & - & - & - & - & - \\
\hline $\begin{array}{l}\text { Paulo } \\
\text { Dalgalarrondo }\end{array}$ & $\begin{array}{l}\text { FCM- } \\
\text { UNICAMP }\end{array}$ & - & - & - & - & - & - \\
\hline
\end{tabular}

* Modest

** Significant

*** Significant: Amounts given to the author's institution or to a colleague for research in which the author has participation, not directly to the author.

Note: FCM-UNICAMP = Faculdade de Ciências Médicas, Universidade Estadual de Campinas.

For more information, see Instructions for Authors.

\section{References}

1. Lipski PE. Rheumatoid arthritis. In: Fauci AS, Braunwald E, Isselbacher KJ, Wilson JD, Martin JB, Kasper DL, Hauser SL, Longo DL, editors. Harrison's principles of internal medicine. 14th ed. New York: MacGraw Hill; 1998. v.2, p.996-2004.

2. Pollard L, Choy EH, Scott DL. The consequences of rheumatoid arthritis: quality of life measures in the individual patient. Clin Exp Rheumatol. 2005;23(5 Suppl 39):S43-52.

3. Sheehy C, Murphy E, Barry M. Depression in rheumatoid arthritis underscoring the problem. Rheumatology. 2006;45(11):1325-7.

4. Blalock SJ, DeVellis RF. Rheumatoid arthritis and depression: an overview. Bull Rheum Dis. 1992;41(1):6-8.

5. Katz PP, Yelin EH. Prevalence and correlates of depressive symptoms among persons with rheumatoid arthritis. J Rheumatol. 1993;20(5):790-6.

6. Fifield J, Reisine S, Sheehan TJ, McQuillan J. Gender, paid work, and symptoms of emotional distress in rheumatoid arthritis patients. Arthritis Rheum. 1996;39(3):427-35.

7. Abdel-Nasser AM, Abd El-Azim S, Taal E, EL-Badawy SA, Rasker JJ, Valkeburg HA. Depression and depressive symptoms in rheumatoid arthritis patients: an analysis of their occurrence and determinants. BrJ Rheumatol. 1998;37(4):391-7.

8. Söderlin MK, Hakala M, Nieminen P. Anxiety and depression in a community-based rheumatoid arthritis population. Scand I Rheumatol. 2000;29(3):177-83.
9. McQuillan J, Fifield J, Sheehan TJ, Reisine S, Tennen H, Hesselbrock V, Rothfield N. A comparison of self-reports of distress and affective disorder diagnoses in rheumatoid arthritis: a receiver operator characteristic analysis. Arthritis Rheum. 2003;49(3):368-76.

10. VanDyke MM, Parker JC, Smarr KL, Hewett JE, Johnson GE, Slaughter JR, Walker SE. Anxiety in rheumatoid arthritis. Arthritis Rheum. 2004;51(3):408-12.

11. Bagnato G, De Filippis LG, Caliri A, Bruno A, Gambardella N, Muscatello MR, Cambria R, Zoccali R. Comparation of levels of anxiety and depression in patients with autoimmune and chronic-degenerative rheumatic: preliminary data. Reumatismo. 2006;58(3):206-11.

12. Schiepers OJ, Wichers MC, Maes M. Cytokines and major depression. Prog Neuropsychopharmacol Biol Psychiatry. 2005;29(2):201-17.

13. Kaufman KR. Etanercept, anticytokines and mania. Int Clin Psychopharmacol. 2005;20(4):239-41.

14. Kahl KG, Bens S, Ziegler K, Rudolf S, Dibbelt L, Kordon A, Schweiger $\mathrm{U}$. Cortisol, the cortisol-dehydroepiandrosterone ratio, and proinflammatory cytokines in patients with current major depressive disorder comorbid with borderline personality disorder. Biol Psychiatry. 2006;59(7):667-71.

15. Weiss DB, Dyrud J, House RM, Beresford TP. Psychiatric manifestations of autoimmune disorders. Curr Treat Options Neurol. 2005;7(5):413-7.

16. Anisman H, Merali Z, Poulter MO, Hayley S. Cytokines as a precipitant of depressive illness: animal and human studies. Curr Pharm Des. 2005;11(8):963-72. 
17. Frank RG, Chaney JM, Clay DL, Shutty MS, Beck NC, Key DR, Elliott TR, Grambling S. Dysphoria: a major symptom factor in persons with disability or chronic illness. Psychiatric Res. 1992;43(3):231-41.

18. Isik A, Koca SS, Ozturk A, Mermi O. Anxiety and depression in patients with rheumatoid arthritis. Clin Rheumatol. 2007;26(6):872-8.

19. Waheed A, Hameed K, Khan AM, Syed JA, Mirza AI. The burden of anxiety and depression among patients with chronic rheumatologic disorders at a tertiary care hospital clinic in Karachi, Pakistan. J Pak Med Assoc. 2006;56(5):243-7.

20. Arnett FC, Edworthy SM, Bloch DA, McShane DJ, Fries JF, Cooper NS, Healey LA, Kaplan SR, Liang MH, Luthra HS. The American Rheumatism Association 1987 revised criteria for the classification of rheumatoid arthritis. Arthritis Rheum. 1988;31(3):315-24.

21. Schnitzer TJ, Lane NE. Osteoarthritis. In: Goldman L, Ausiello D, editors. Cecil text book of medicine. 22nd ed. Philadelphia: W. B. Sauders Company; 2004. v.2, p.1698-702.

22. Zigmond AS, Snaith RP. The Hospital anxiety and depression scale. Acta Psychiatr Scand. 1983;67:361-70.

23. Botega NJ, Dalgalarrondo P. Avaliação do paciente. In: Botega NJ. Prática psiquiátrica no hospital geral: interconsulta e emergência. 2nd ed. Porte Alegre: Artmed; 2002. p.155-82.

24. Botega NJ, Bio MR, Zomignami MA Garcia C Jr, Pereira WA. Mood disorders among inpatients in ambulatory and validation of the anxiety and depression scale HAD. Rev Saude Publica. 1995;29(5):355-63.

25. Ferraz MB, Oliveira LM, Araujo PM, Atra E, Tugwell P. Crosscultural reliability of the physical ability dimension of the health assessment questionnaire. J Rheumatol. 1990;17(6):813-7.

26. Wolfe F, Kleinheksel SM, Cathey MA, Hawley DJ, Spitz PW, Fries JF. The clinical value of the Stanford Health Assessment Questionnaire Functional Disability Index in patients with rheumatoid arthritis. $J$ Rheumatol. 1988;15(10):1480-8.

27. van Gestel AM, Prevoo ML, van't Hof MA, van Rijswijk MH, van de Putte LB, van Riel PL. Development and validation of the European league against rheumatism response criteria for rheumatoid arthritis. Comparison with the preliminary American College of Rheumatology and the World Health Organization/International league Against Rheumatism Criteria. Arthritis Rheum. 1996;39(1):34-40.

28. Bértolo M, Cicconelli R, Laurindo I, Castelar G, Rodominski S, Xavier R, Clark O, Sasse EC. Uso de agentes biológicos para o tratamento da artrite reumatóide: melhores evidências e recomendaçôes para a prática clínica. Rev Bras Med. 2005;62:158-65.

29. Hennekens CH. Epidemiology in medicine. Boston: Little, Brown and Company; 1987. 